\title{
CHANGES OF PETROLEUM HYDROCARBON IN JIAOZHOU BAY 1984-1988
}

\author{
YANG, D. F. ${ }^{1,2^{*}}$ - LI, H. X. ${ }^{1}-$ ZHANG, L. L. ${ }^{1}-$ ZHAO, L. G. ${ }^{1}-$ WANG, Q. ${ }^{1}$ \\ ${ }^{1}$ Accountancy School, Xijing University, 710123 Xian, China \\ ${ }^{2}$ North China Sea Environmental Monitoring Center, SOA, 266033 Qingdao, China \\ *Corresponding author \\ e-mail:dfyang_dfyang@126.com \\ (Received 22 ${ }^{\text {nd }}$ Mar 2018; accepted $30^{\text {th }}$ May 2018)
}

\begin{abstract}
Petroleum hydrocarbon (PHC) pollution in marine bays has been one of the critical environmental issues in many countries and regions. Jiaozhou Bay is a semi-closed bay in the fastgrowing region in eastern China and has been contaminated by a variety of pollutants after the 1980s. Using investigation data in this bay during 1981-1988, this paper analyzed the temporal, spatial and seasonal changes of PHC. Results showed that PHC contents in surface waters during 1984-1988 were $0.01-0.16 \mathrm{mgL}^{-1}, 0.025-0.124 \mathrm{mgL}^{-1}, 0.005-0.122 \mathrm{mgL}^{-1}, 0.014-0.091 \mathrm{mgL}^{-1}$ and $0.005-0.178 \mathrm{mgL}^{-1}$, respectively. The pollution level of PHC during 1984-1988 was moderate and was changing with seasons due to the variations of source input. Low values of PHC contents during 1984-1988 were all closed to $0.005 \mathrm{mgL}^{-1}$, and this value could be considered as the 'background' value of PHC. High values of PHC contents in spring during this period tended to be stable, yet in summer and autumn during this period tended to be increasing. Stream discharge was the major source of PHC, and marine traffic and marine itself were also responsible. The source strengths were still slight/moderate in according to Chinese Sea Water Quality Standard (GB 3097-1997). Stream discharge was one of the major sources of PHC in every year, and the source strengths were increasing along with time. PHC in this bay was mainly input from rainfall runoff. Marine traffic had been one of the important sources since the 1980s, indicated that the oil leaking from marine traffic should be paid attention to. Marine current was also one of the important sources, and the source strengths could be as high as $0.122 \mathrm{mgL}^{-1}$. Rainfall runoff was the major force of various pollutants to the marine bay, the source input of PHC was also in order of summer > spring > autumn > winter. This was the major reason to explain the seasonal variations of PHC contents in Jiaozhou Bay. The background value of PHC in the marine bay was $0.005 \mathrm{mgL}^{-1}$, and the increase of PHC contents in the ocean could be calculated as $0.122-0.005=0.117 \mathrm{mgL}^{-1}$. This was the results of the storage of PHC in the ocean. The control and management of anthropogenic source input of PHC in the marine bay were necessary. The outcome of this paper is to identify the major sources, to define the annual change trend and the spatial-seasonal variations, to assess the storage of PHC in the marine bay, and to provide a basis for environmental management decision-making.
\end{abstract}

Keywords: spatial, seasonal, annual, pollution, source

\section{Introduction}

Along with the rapid development of industry, agriculture and traffic, a great deal of waste gas, water and residue are generated and discharged to air, soil and water environment (Yang et al., 2002, 2013a). The problem of marine pollution is tending to be more and more serious since the ocean is the "sink" of pollutants (Yang and Miao, 2010; Yang and Gao, 2010). PHC is widely used in industry, agriculture and traffic (Yang et al., 2014). By means of stream discharge, atmospheric deposition and oil spilling, many marine bays have been polluted by PHC and have caused serious environmental problems (Yang et al., 2014, 2015a). Identifying the major anthropogenic sources, the annual change trend and the spatial-seasonal variations is essential to marine environmental protection. 
Jiaozhou Bay is a semi-closed bay located in the south of Shandong Peninsula in eastern China and is surrounded by cities of Jiaozhou, Jiaonan and Qingdao in the north, west and east, respectively. This bay has been contaminated after the 1980s, and previous studies showed that this bay has been polluted by various pollutants including $\mathrm{Pb}$ (Yang et al., 2008a, 2011a), Hg (Yang et al., 2008b, 2013b), HCH (Yang et al., 2011b, 2015b, 2015c), Cu (Yang et al., 2015d, 2015e). Using investigation data of the bay during 1981-1988, this paper analyzed the temporal, spatial and seasonal changes of PHC. The aim of this paper is to provide a basis for environmental management decision-making.

\section{Materials and methods}

\section{Study area}

Jiaozhou Bay $\left(120^{\circ} 04^{\prime}-120^{\circ} 23^{\prime} \mathrm{E}, 35^{\circ} 55^{\prime}-36^{\circ} 18^{\prime} \mathrm{N}\right)$ is in the south of Shandong Province, eastern China (Fig. 1). It is a semi-closed bay with the total area, average water depth and bay mouth width of $446 \mathrm{~km}^{2}, 7 \mathrm{~m}$ and $3 \mathrm{~km}$, respectively. There are more than ten inflow rivers such as Haibo River, Licun River, Dagu River, and Loushan River etc., most of which have seasonal features (Yang et al., 2005, 2004).

\section{Data collection}

Data on PHC contents in Jiaozhou Bay were provided by North China Sea Environmental Monitoring Center. The investigation was conducted in July, August and October 1984 (Fig. 1), April, July and October 1985 (Fig. 1), April, July and October 1986 (Fig. 1), May, July and November 1987 (Fig. 1), and April, July and October 1988 (Fig. 2). Surface water samples were collected and measured by the National Specification for Marine Monitoring (China's State Oceanic Administration, 1991).

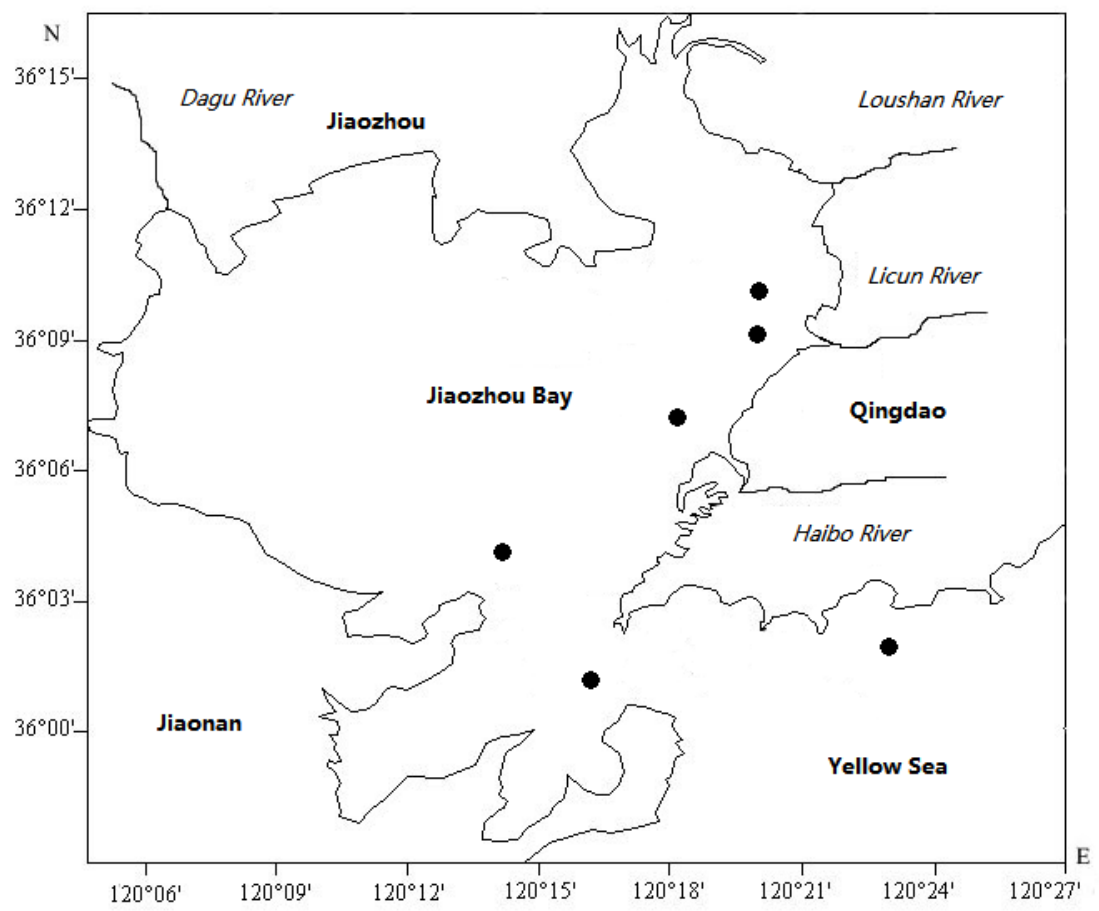

Figure 1. Geographic location of Jiaozhou Bay and monitoring sites in 1984-1987 


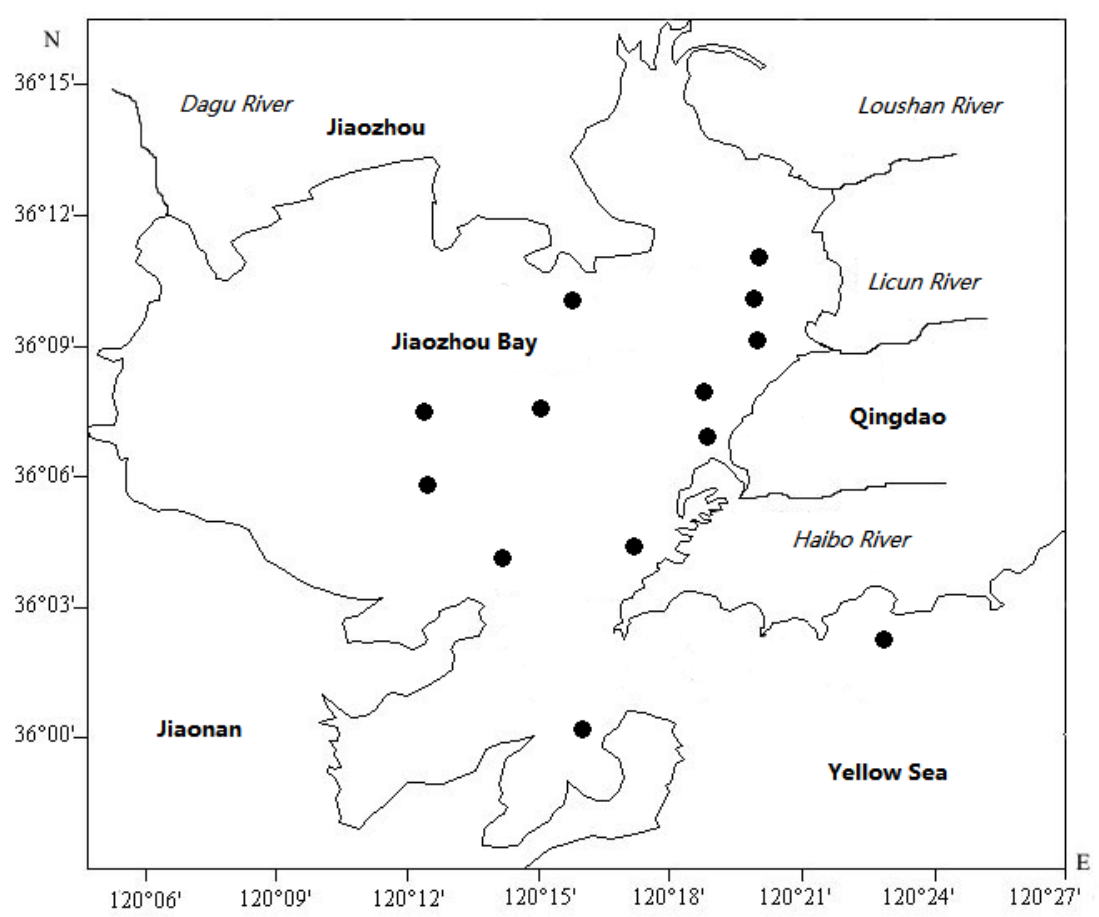

Figure 2. Geographic location of Jiaozhou Bay and monitoring sites in 1984-1987

\section{Results and discussion}

\section{Annual changes of PHC}

PHC contents in surface waters during 1984-1988 were $0.01-0.16 \mathrm{mgL}^{-1}, 0.025$ $0.124 \mathrm{mgL}^{-1}, \quad 0.005-0.122 \mathrm{mgL}^{-1}, 0.014-0.091 \mathrm{mgL}^{-1}$ and $0.005-0.178 \mathrm{mgL}^{-1}$, respectively. In the guidelines for PHC in Chinese Sea Water Quality Standard (GB 3097-1997), there are 4 classes of water quality: Class I (and II), III and IV (Table 1). PHC contents in surface waters in July, August and October 1984 were 0.050$0.060 \mathrm{mgL}^{-1}, 0.090-0.160 \mathrm{mgL}^{-1}$ and $0.010-0.050 \mathrm{mgL}^{-1}$, and were Class I (and II), Class III and Class I (and II), respectively. PHC contents in surface waters in April, July and October 1985 were $0.025-0.064 \mathrm{mgL}^{-1}, 0.059-0.124 \mathrm{mgL}^{-1}$ and $0.010-0.121 \mathrm{mgL}^{-1}$, belonged to Class I (and II), Class III and Class I (and II), respectively. PHC contents in surface waters in April, July and October 1986 were $0.005-0.066 \mathrm{mgL}^{-1}, 0.022$ $0.122 \mathrm{mgL}^{-1}$ and $0.005-0.017 \mathrm{mgL}^{-1}$, belonged to Class I to III, Class I to III and Class I (and II), respectively. PHC contents in surface waters in May, July and November 1987 were $0.014-0.060 \mathrm{mgL}^{-1}, 0.016-0.066 \mathrm{mgL}^{-1}$ and $0.030-0.091 \mathrm{mgL}^{-1}$, all ranging from Class I to III. PHC contents in surface waters in April, July and October 1988 were 0.014-0.064 mgL $\mathrm{mg}^{-1}, 0.005-0.178 \mathrm{mgL}^{-1}$ and $0.022-0.169 \mathrm{mgL}^{-1}$, all ranging from Class I to III. In general, the pollution level of PHC during 1984-1988 was moderate (Table 2) and was changing with seasons due to the seasonal variations of source input.

Table 1. Guidelines for PHC in Chinese Sea Water Quality Standard (GB 3097-1997)

\begin{tabular}{c|c|c|c}
\hline Class & I (and II) & III & IV \\
\hline Guideline & 0.05 & 0.30 & 0.50 \\
\hline
\end{tabular}


Table 2. Water quality of PHC in different seasons in Jiaozhou Bay 1984-1988

\begin{tabular}{c|c|c|c}
\hline Year & Spring & Summer & Autumn \\
\hline 1984 & - & I, II, III & I, II, III \\
1985 & I, II, III & I, II, III & I, II, III \\
1986 & I, II, III & I, II, III & I, II \\
1987 & I, II, III & I, II, III & I, II, III \\
1988 & I, II, III & I, II, III & I, II, III \\
\hline
\end{tabular}

\section{Temporal changes of $\mathrm{PHC}$}

In the area of study, April, May and June belong to spring, July, August and September belong to summer, and October, November and December belong to autumn. During 1984-1988, PHC contents in spring, summer and autumn were 0.005$0.066 \mathrm{mgL}^{-1}, 0.005-0.178 \mathrm{mgL}^{-1}$ and $0.005-0.169 \mathrm{mgL}^{-1}$, respectively. According to the high values, PHC contents in different seasons were in order of summer > autumn > spring. The high values of PHC contents in different seasons during 1984-1988 were showed in Figure 3. It could be seen that high values of PHC contents in spring during this period tended to be stable, yet in summer and autumn during this period tendes to be increasing. In general, high values of PHC contents during 1984-1988 tended to be increasing. The seasonal changes of PHC contents indicated that the source inputs of PHC in this bay were relative high in summer and autumn yet was relatively low in spring. The reason was that summer and autumn were the wet seasons and a lot of PHC was discharged to Jiaozhou Bay via rainfall-runoff. Meanwhile, the atmospheric deposition of PHC to Jiaozhou Bay was increasing in the wet seasons. In according to the temporal changes of PHC contents in different seasons, it could be found that the pollution levels of PHC tended to be more and more serious along with time. It should be noticed that the low values of PHC contents during 1984-1988 were all closed to $0.005 \mathrm{mgL}^{-1}$, and this value could be considered as the 'background' value of PHC in Jiaozhou Bay. PHC contents in surface waters were directly impacted by source inputs and these trends indicated that the anthropogenic input of PHC was increasing along with the rapid development of industry around this bay, and the source control of PHC was essential to improve the water quality.

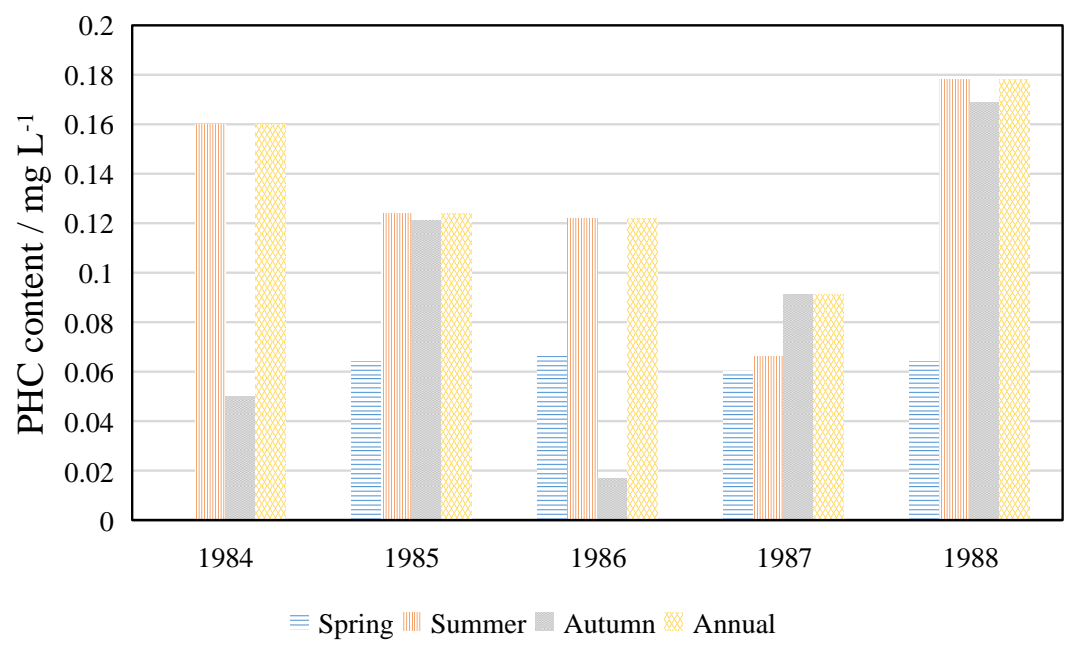

Figure 3. High values of PHC contents in different seasons in Jiaozhou Bay 1984-1988 


\section{Horizontal distributions of PHC}

The contents of PHC in surface waters are mainly impacted by the source input, and the high-value regions are the key evidence to identify the sources. In July, August and October 1984, the high-value regions of PHC contents were in the estuary of the Haibo River $\left(0.060 \mathrm{mgL}^{-1}\right)$, the estuary of the Loushan River $\left(0.160 \mathrm{mgL}^{-1}\right)$ and the estuary of the Loushan River $\left(0.050 \mathrm{mgL}^{-1}\right)$, respectively. In April, July and October 1985, the high-value regions of PHC contents were in the estuary of the Licun River $\left(0.064 \mathrm{mgL}^{-}\right.$ $\left.{ }^{1}\right)$, the estuary of the Haibo River $\left(0.124 \mathrm{mgL}^{-1}\right)$ and the estuary of the Licun River (0.121 $\left.\mathrm{mgL}^{-1}\right)$, respectively. In April, July and October 1986, the high-value regions of PHC contents were in the estuary of the Loushan River $\left(0.066 \mathrm{mgL}^{-1}\right)$, open waters $\left(0.122 \mathrm{mgL}^{-1}\right)$ and the estuary of the Licun River $\left(0.017 \mathrm{mgL}^{-1}\right)$, respectively. In May, July and November 1987, the high-value regions of PHC contents were in the southwest coast $\left(0.060 \mathrm{mgL}^{-1}\right)$, the estuary of the Loushan River $\left(0.066 \mathrm{mgL}^{-1}\right)$ and the southwest coast $\left(0.091 \mathrm{mgL}^{-1}\right)$, respectively. In April, July and October 1988, the high-value regions of PHC contents were in the estuary of the Licun River $\left(0.064 \mathrm{mgL}^{-1}\right)$, the estuary of the Haibo River $\left(0.178 \mathrm{mgL}^{-1}\right)$ and the estuary of the Haibo River $\left(0.169 \mathrm{mgL}^{-1}\right)$, respectively.

\section{Sources of PHC}

In general, the horizontal distributions of PHC in surface waters are mainly impacted by the source input, and PHC contents are always decreasing along the way from the high-value regions towards areas far away. In July 1984, PHC contents were decreasing from the estuary of Haibo River in the northeast of the bay to the south of the bay (Fig. 4), indicating that stream discharge was one of the major sources. In April 1985, PHC contents were decreasing from the estuary of Licun River in the northeast of the bay to the south of the bay (Fig. 5), indicating that stream discharge was one of the major sources.

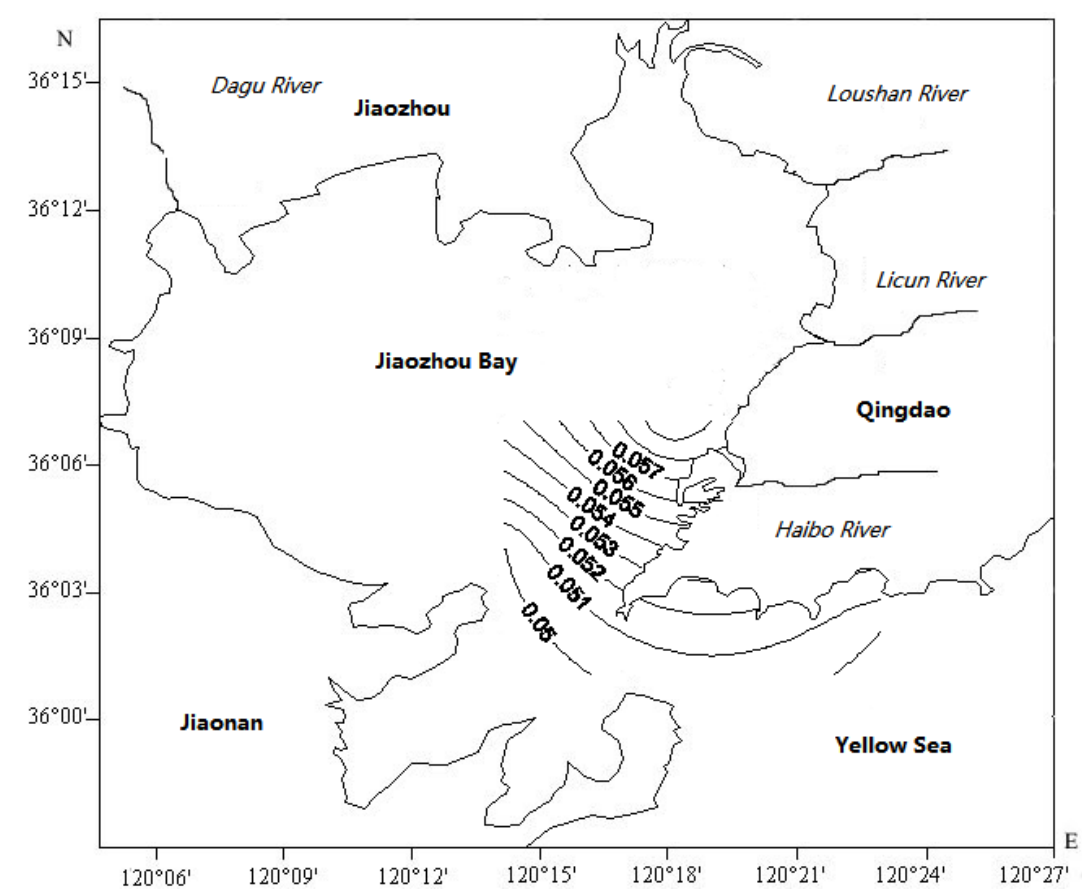

Figure 4. Horizontal distribution of PHC in surface waters in Jiaozhou Bay in July 1984/mgL-1 


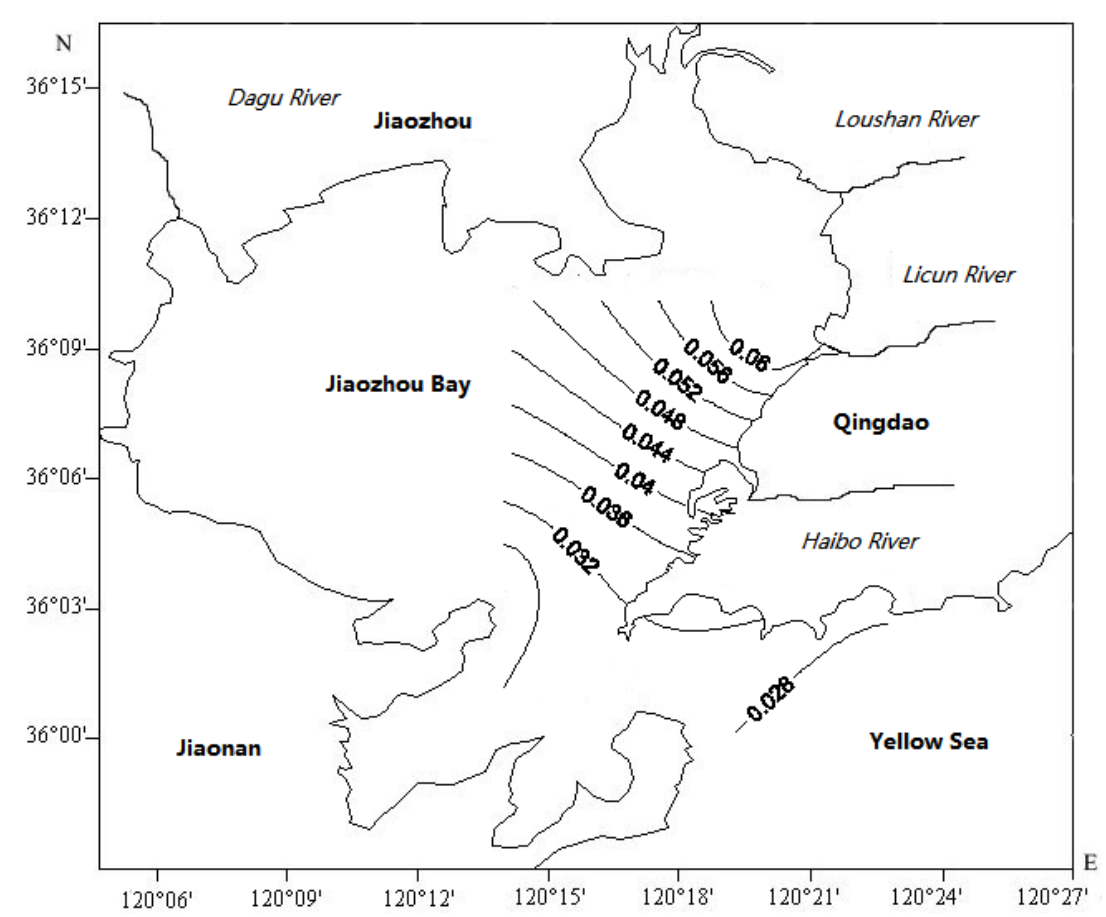

Figure 5. Horizontal distribution of PHC in surface waters in Jiaozhou Bay in April 1985/mgL ${ }^{-1}$

In July 1986, PHC contents were decreasing from the open waters to the inside of the bay (Fig. 6), indicating that marine current was one of the major sources. In November 1987, PHC contents were decreasing from the southwest coast where there was an important harbour to the northeast of the bay (Fig. 7), indicating that marine traffic was one of the major sources.

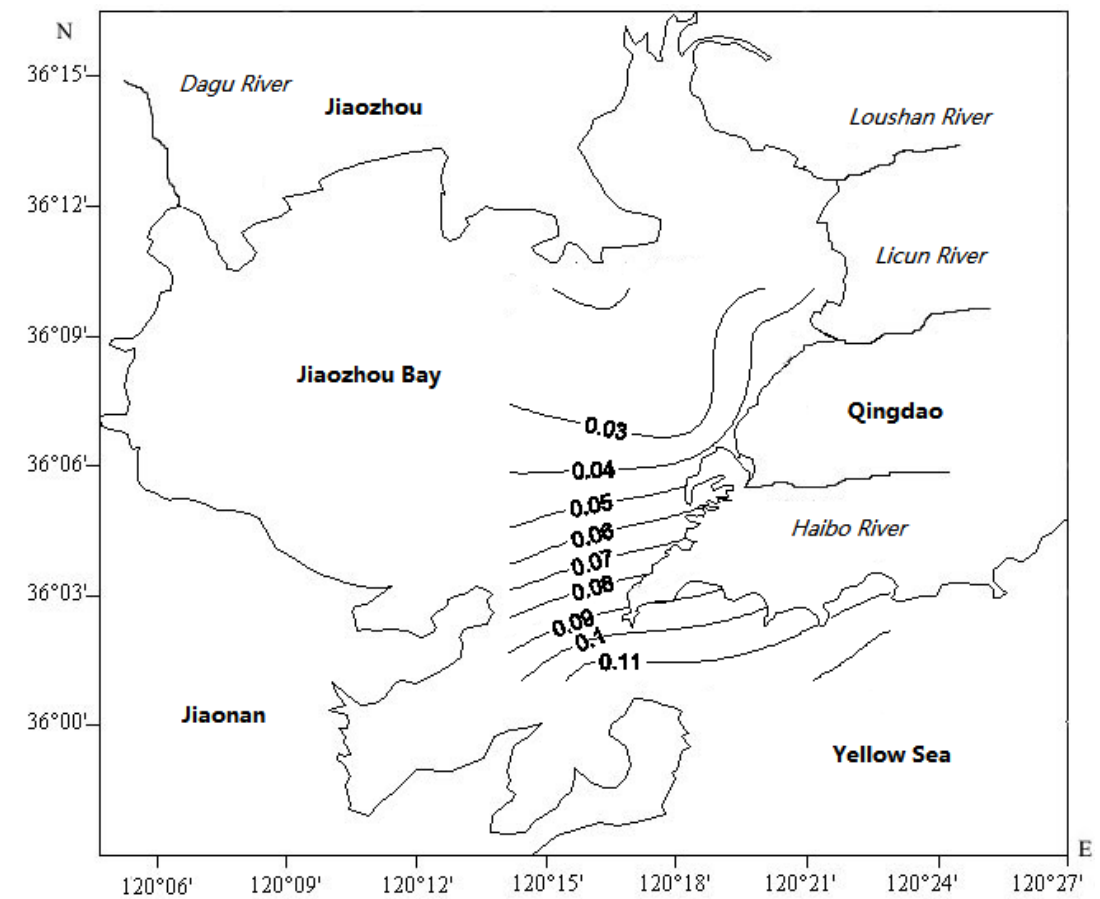

Figure 6. Horizontal distribution of PHC in surface waters in Jiaozhou Bay in July 1986/mgL ${ }^{-1}$ 


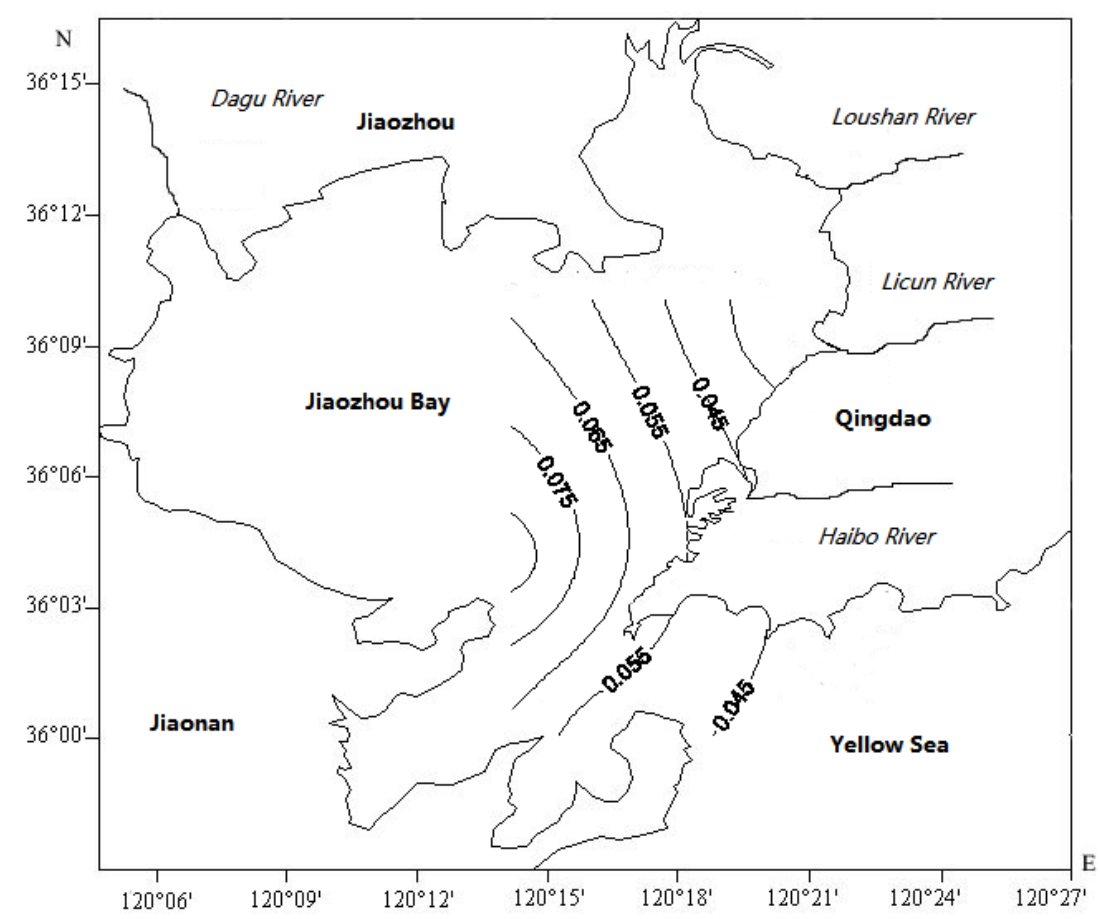

Figure 7. Horizontal distribution of PHC in surface waters in Jiaozhou Bay in November $1987 / \mathrm{mg} \mathrm{L}^{-1}$

In July 1988, PHC contents were decreasing from the estuary of Haibo River to the center of the bay (Fig. 8), indicating that stream discharge was one of the major sources. In general, stream discharge was the major source of PHC, and marine traffic and the sea itself were also responsible (Table 3).

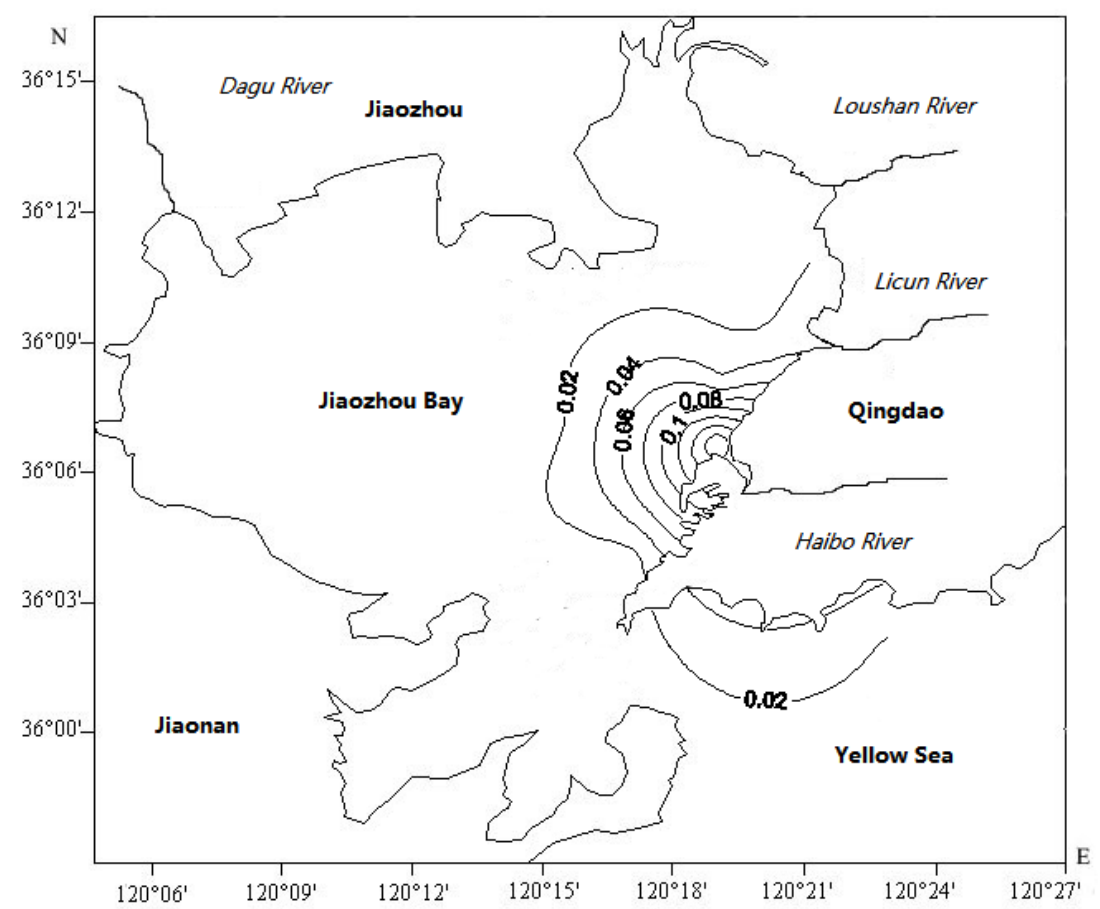

Figure 8. Horizontal distribution of PHC in surface waters in Jiaozhou Bay in July 1988/mg $L^{-1}$ 
Table 3. Sources and source strengths of PHC in Jiaozhou Bay 1984-1988

\begin{tabular}{c|c|c|c}
\hline Year & Month & Source & Source strength \\
\hline \multirow{3}{*}{1984} & July & Haibo River & 0.060 \\
& August & Loushan River & 0.160 \\
& October & Loushan River & 0.050 \\
& April & Licun River & 0.064 \\
& July & Haibo River & 0.124 \\
\multirow{3}{*}{1985} & October & Licun River & 0.121 \\
& April & Loushan River & 0.066 \\
& July & Marine current & 0.122 \\
& October & Licun River & 0.017 \\
& May & Marine traffic & 0.060 \\
& July & Loushan River & 0.066 \\
& November & Marine traffic & 0.091 \\
& April & Licun River & 0.064 \\
& July & Haibo River & 0.178 \\
& October & Haibo River & 0.169 \\
\hline
\end{tabular}

\section{Changes of PHC's sources}

In 1984, the major source of PHC in Jiaozhou Bay was stream discharge, whose source strength was 0.05-0.16 $\mathrm{mgL}^{-1}$. In 1985, the major source of PHC in Jiaozhou Bay was stream discharge, whose source strength was $0.064-0.124 \mathrm{mgL}^{-1}$. In 1986, the major sources of PHC in Jiaozhou Bay were stream discharge and marine current, whose source strength was $0.017-0.066 \mathrm{mgL}^{-1}$ and $0.122 \mathrm{mgL}^{-1}$, respectively. In 1987 , the major sources of PHC in Jiaozhou Bay were stream discharge and marine traffic, whose source strength was $0.066 \mathrm{mg} \mathrm{L}^{-1}$ and $0.060-0.091 \mathrm{mg}^{-1} \mathrm{~L}^{-1}$, respectively. In 1988 , the major source of PHC in Jiaozhou Bay was stream discharge, whose source strength was 0.064-0.178 $\mathrm{mgL}^{-1}$. In general, there were three sources of PHC, i.e., stream discharge, marine current and marine, and the source strength was still slight/moderate in according to Chinese Sea Water Quality Standard (GB 3097-1997) (Table 4). For annual changes, stream discharge was one of the major sources of PHC in every year, and the source strengths were increasing along with time. Hence, it could be concluded that PHC in this bay was mainly input from rainfall runoff. However, marine traffic had been one of the important sources since the 1980s, indicating that oil leaking from marine traffic should be paid attention to. Furthermore, the marine current was also one of the important sources, and the source strengths could be as high as $0.122 \mathrm{mg} \mathrm{L}^{-1}$ during the 1980s. This indicated the ocean had been strongly impacted by anthropogenic source input of PHC. Once the ocean was polluted, the remediation of water quality would be a task and long-term work. As a whole, source control should be promoted.

Table 4. Pollution levels of PHC's sources in Jiaozhou Bay 1984-1988

\begin{tabular}{c|c|c|c|c|c}
\hline \multirow{2}{*}{ Source } & \multicolumn{3}{|c|}{ Stream discharge } & \multirow{2}{*}{ Marine current } & \multirow{2}{*}{ Marine traffic } \\
\cline { 2 - 6 } & Loushan River & Licun River & Haibo River & & \\
\hline Source strength & $0.050-0.160$ & $0.017-0.121$ & $0.060-0.178$ & 0.122 & $0.060-0.091$ \\
Pollution level & Slight & Slight & Moderate & Moderate & Slight \\
\hline
\end{tabular}


During the period of study, the seasonal variation of precipitation was very significant (Fig. 9). The maximum and minimum amount of precipitation occurred in summer and winter, respectively. For monthly variations, the amount of precipitation was the lowest in in January $(11.8 \mathrm{~mm})$, and was increasing to a relatively high value in April $(33.4 \mathrm{~mm})$, and was reaching the maximum amount in August $(150.3 \mathrm{~mm})$, and then was decreasing to a relatively low in November (23.4), and finally was reaching the minimum in January in January again. In general, the periods of precipitation were in order of summer $>$ spring $>$ autumn $>$ winter, resulting in a river discharge which was also in order of summer $>$ spring $>$ autumn $>$ winter. Since rainfall runoff was the major force of various pollutants to the marine bay, the source input of PHC was also in order of summer > spring > autumn > winter. This was the major reason for the seasonal variations of PHC contents in Jiaozhou Bay.

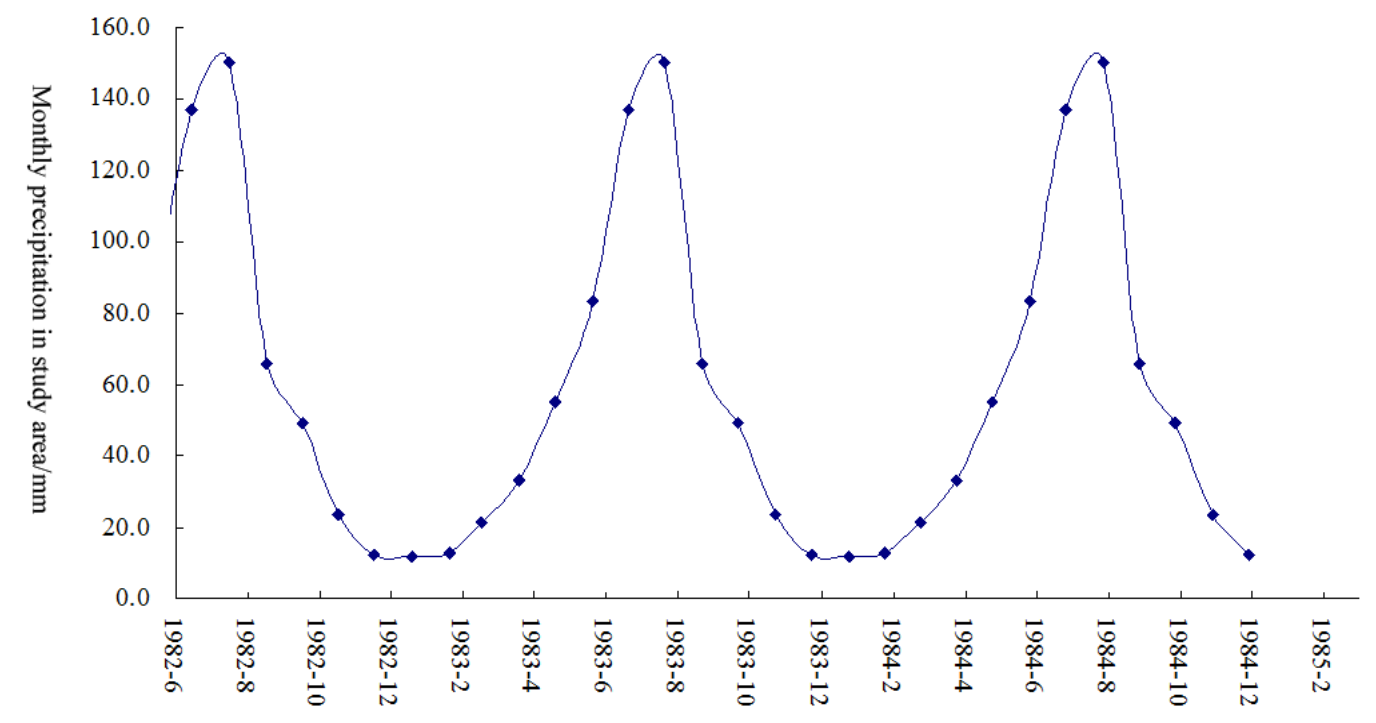

Figure 9. Monthly precipitation in study area/mm

\section{Storage of PHC}

In general, precipitation determined the river discharge, river discharge determined the source input of PHC, resulting in the seasonal variations of PHC in Jiaozhou Bay waters. By means of the continuous source input of $\mathrm{PHC}$ from river discharged, and the continuous accumulation of PHC in waters, a great deal of PHC was stored in Jiaozhou Bay, resulting in the increasing trend of PHC contents in waters. However, in 1987, PHC contents in waters were mainly impacted bay source input of marine traffic, resulting in different seasonal distribution patterns. In case of little source input, the background value of PHC in this bay was $0.005 \mathrm{mgL}^{-1}$, while in case of source input from marine current, the high-value was $0.122 \mathrm{mgL}^{-1}$. In consideration that the background value of PHC was $0.005 \mathrm{mgL}^{-1}$ and the background value of PHC in marine was $\mathrm{mgL}^{-1}$, the increase of PHC contents in the ocean could be calculated as 0.122 $0.005=0.117 \mathrm{mgL}^{-1}$. This was the results of the storage of PHC in the ocean. Furthermore, a block diagram model was provided to demonstrate that PHC contents in marine waters were increasing continuously by means of continuous source input (Fig. 10). Hence, the control and management of anthropogenic source input of PHC in the marine bay were necessary. 


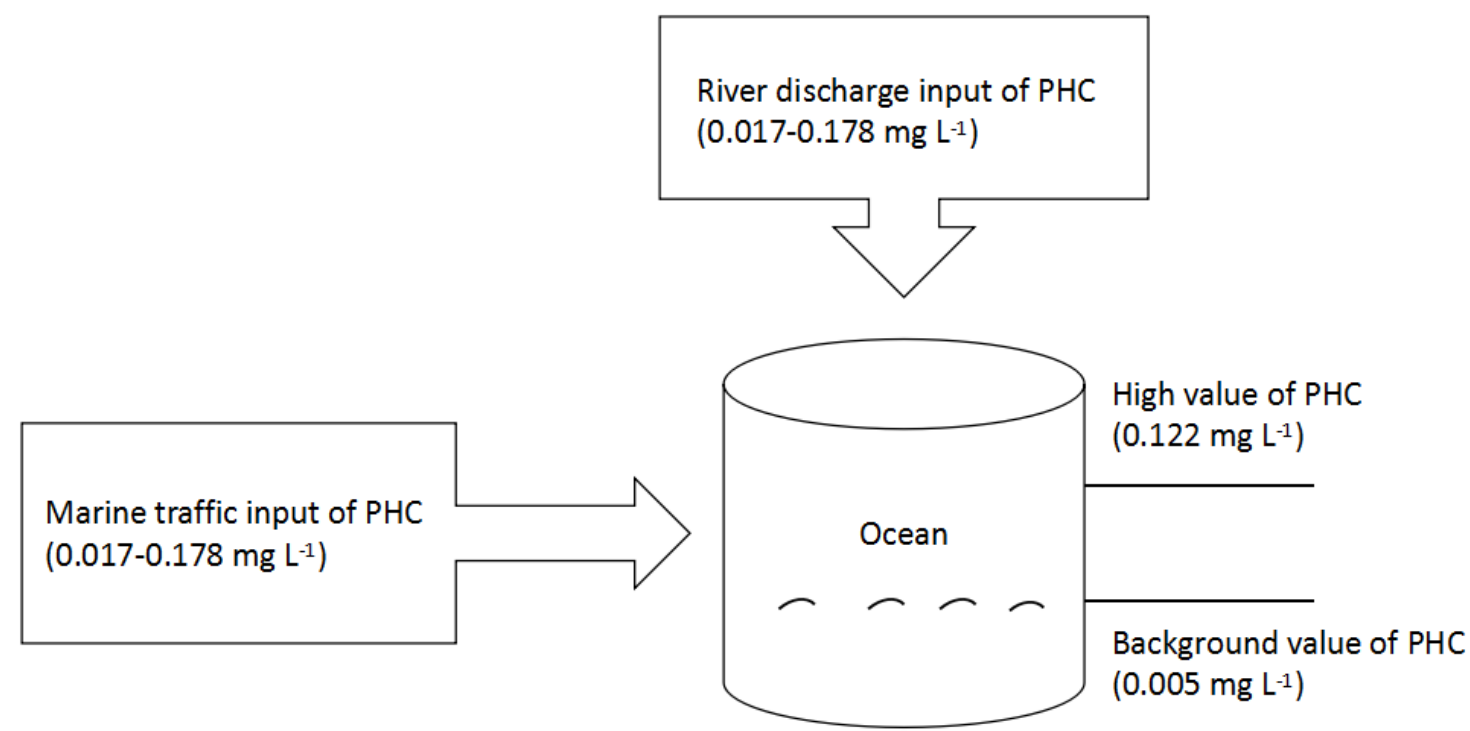

Figure 10. Block diagram model for the influence of PHC input on marine PHC content

\section{Conclusion}

PHC during 1984-1988 was 0.01-0.16 mgL ${ }^{-1}, 0.025-0.124 \mathrm{mgL}^{-1}, 0.005-0.122 \mathrm{mgL}^{-}$ ${ }^{1}, 0.014-0.091 \mathrm{mgL}^{-1}$ and $0.005-0.178 \mathrm{mgL}^{-1}$, respectively. The pollution level of PHC during 1984-1988 was moderate and was changing with seasons due to the seasonal variations of source input. Low values of PHC contents during 1984-1988 were all closed to $0.005 \mathrm{mgL}^{-1}$, and these values could be considered as the 'background' values of PHC in Jiaozhou Bay. High values of PHC contents in spring during this period tends to be stable, yet in summer and autumn during this period were tending to be increasing. The pollution levels of PHC tends to be more and more serious along with time, and the source control of PHC is essential to improve the water quality.

The sources of PHC in Jiaozhou Bay during 1984-1988 were identified. Stream discharge was the major source of PHC, and marine traffic and marine were also responsible. The source strengths were still slight/moderate in according to Chinese Sea Water Quality Standard (GB 3097-1997). Stream discharge was one of the major sources of PHC in every year, and the source strengths were increasing along with time. PHC in this bay was mainly input from rainfall runoff. Marine traffic had been one of the important sources since the 1980s, indicated that oil leaking from marine traffic should be paid attention to. Marine current was also one of the important sources, and the source strengths could be as high as $0.122 \mathrm{mgL}^{-1}$ during the $1980 \mathrm{~s}$. Source control should be promoted.

Rainfall runoff was the major force of various pollutants to the marine bay, the source input of $\mathrm{PHC}$ was also in order of summer $>$ spring $>$ autumn $>$ winter. This was the major reason for the seasonal variations of PHC contents in Jiaozhou Bay. The background value of PHC was $0.005 \mathrm{mgL}^{-1}$ and that in marine was $\mathrm{mgL}^{-1}$, the increase of PHC contents in the ocean could be calculated as $0.122-0.005=0.117 \mathrm{mgL}^{-1}$. This was the results of the storage of PHC in the ocean. Furthermore, a block diagram model was provided to demonstrate that PHC contents in marine waters were increasing continuously by means of continuous source input. Hence, the control and management of anthropogenic source input of PHC in the marine were necessary. 
Acknowledgements. This research was sponsored by Doctoral Degree Construction Library of Guizhou Nationalities University, Research Projects of Guizhou Nationalities University ([2014]02), Research Projects of Guizhou Province Ministry of Education (KY [2014] 266), Research Projects of Guizhou Province Ministry of Science and Technology (LH [2014] 7376).

\section{REFERENCES}

[1] China's State Oceanic Administration (ed.) (1991): The Specification for Marine Monitoring. - Ocean Press, Beijing.

[2] Yang, D. F., Miao, Z. Q. (ed.) (2010): Marine Bay Ecology (I). - Ocean Press, Beijing.

[3] Yang, D. F., Gao, Z. H. (ed.) (2010): Marine Bay Ecology (I). - Ocean Press, Beijing.

[4] Yang, D. F., Zhang, Y. C., Zou, J., Yang, H. (2002): Contents and distribution of petroleum hydrocarbons (PHC) in Jiaozhou Bay waters. - Open Journal of Marine Science 2(3): 108-112.

[5] Yang, D. F., Wang, F., Gao, Z. H., Cui, W. L., Huo, S. X. (2004): Ecological phenomena of phytoplankton in Jiaozhou Bay. - Marine Science 28(6): 71-74.

[6] Yang, D. F., Chen, Y., Gao, Z. H., Zhang, J., Wang, F. (2005): SiLicon limitation on primary production and its destiny in Jiaozhou Bay, China IV transect offshore the coast with estuaries. - Chinese Journal of Oceanology and Limnology 23(1): 72-90.

[7] Yang, D. F., Chang, S., Gao, Z. H., Sun, P. Y., Cao, L. X. (2008a): Pb distribution and translocation in Jiaozhou Bay. - Chinese Journal of Oceanology and Limnology 26(3): 296-299.

[8] Yang, D. F., Cao, H. R., Gao, Z. H., Lu, Q., Qu, Y. F. (2008b): Hg in Jiaozhou Bay I. Distribution and transition. - Marine Environmental Science 27(1): 37-39.

[9] Yang, D. F., Guo, J. H., Zhang, Y. J., Ding, Z. R., Bu, Z. G.(2011a): Pb distribution and sources in Jiaozhou Bay, East China. - Journal of Water Resource and Protection 3(1): 41-49.

[10] Yang, D. F., Zhang, Y. C., Zou, J., Zhou, Q., Yang, H. L. (2011b): Contents and distribution of petroleum hydrocarbons (PHC) in Jiaozhou Bay waters. - Open Journal of Marine Science 2(3): 108-112.

[11] Yang, D. F., Sun, P. Y., Chen, C., Bai, H. Y., Zhou, Q. (2013a): Distributions and sources of PHC in Jiaozhou Bay. - Coastal Engineering 32(1): 60-72.

[12] Yang, D. F., Sun, P. Y., Ju, L., Zhao, Y. H., Qu, Y. F. (2013b): Content and distribution of $\mathrm{Hg}$ in the water of the Jiaozhou Bay. - Coastal Engineering 32(4): 65-76.

[13] Yang, D. F., Sun, P. Y., Ju, L., Wang, C. H., Liu, Y. L. (2014): Distribution and changing of petroleum hydrocarbon in Jiaozhou Bay waters. - Applied Mechanics and Materials 644-650: 5312-5315.

[14] Yang, D. F., Wu, F. Y., He, H. Z., Zhu, S. X., Wang, F. Y. (2015a): Vertical distribution of Petroleum Hydrocarbon in Jiaozhou Bay. - Proceedings of the 2015 International Symposium on Computers and Informatics, Beijing, pp. 2647-2654.

[15] Yang, D. F., Wang, F. Y., Zhu, S. X., Zhao, X. L., Luo, J. L. (2015b): Distribution and homogeneity of petroleum hydrocarbon in Jiaozhou Bay. - Proceedings of the 2015 International Symposium on Computers and Informatics, Beijing, pp. 2661-2666.

[16] Yang, D. F., Sun, P. Y., Ju, L., Yu, Q. Y., Cao, J. (2015c): Input features of petroleum hydrocarbon in Jiaozhou Bay. - Proceedings of the 2015 International Symposium on Computers and Informatics, Beijing, pp. 2675-2680.

[17] Yang, D. F., Miao, Z., Song, W., Xu, Z., Geng, X. (2015d): Research on the sources of $\mathrm{Cu}$ in Jiaozhou Bay. - Advanced Materials Research 1092-1093: 1013-1016.

[18] Yang, D. F., Miao, Z., Cui, W., Zheng, L., Chen, S. (2015e): Input and transfer processes of $\mathrm{Cu}$ in bay waters. - Advances in Intelligent Systems Research 2015: 17-20. 